\title{
Optimizing a novel method for manual tree falling
}

\author{
by C. Kevin Lyons ${ }^{1}$ and Florian Noll²
}

\begin{abstract}
This paper reports the results from work done to optimize a novel manual tree falling method that uses uncut strips of wood on the backcut side of the tree to restrain the tree while the faller is at the base, and then uses a remotely operated hydraulic flange spreader to initiate falling. This paper found the optimal target length of the uncut strips was $7.5 \mathrm{~cm}$, one uncut strip was just as effective as two, and that one uncut strip was much simpler for the faller to cut.
\end{abstract}

Key words: tree falling, flange spreader, holding wood design

\section{RÉSUMÉ}

Cet article porte sur les résultats de travaux réalisés pour optimiser une nouvelle méthode d'abattage manuel des arbres qui comporte la réalisation d’entailles partielles sur le côté de l'arbre opposé au côté de la coupe pour le retenir alors que l'abatteur est à l'ouvre à la base, et qui est suivie de l'utilisation d'un écarteur hydraulique pour amorcer la chute. Larticle indique que la longueur cible optimale des entailles partielles est de $7,5 \mathrm{~cm}$ et qu'une entaille incomplète est aussi efficace que deux tout en étant beaucoup plus simple à réaliser pour labatteur.

Mots clés : abattage d’arbre, écarteur, principe de retenu

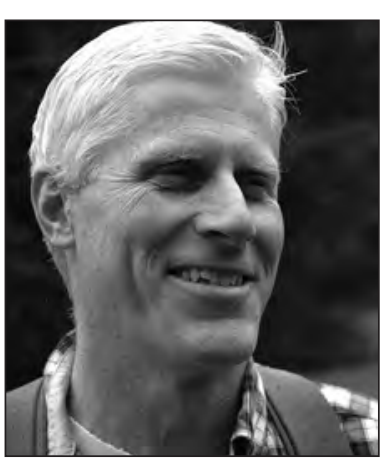

C. Kevin Lyons

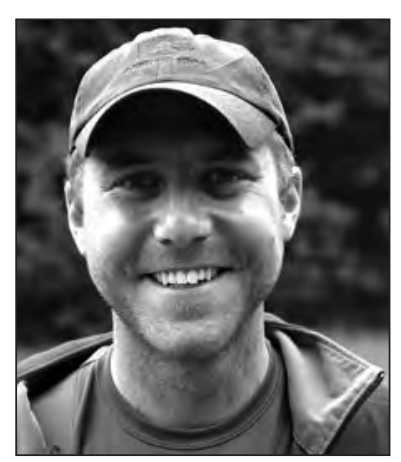

Florian Noll

\section{Introduction}

Manual tree falling is considered to be one of the most dangerous professions in the forest industry, especially in the Pacific Northwest (Paulozzi 1987; WorkSafeBC 2004 2009). Unseen debris falling out of the canopy is one of the most common causes of fatalities and serious injuries when manually falling trees (Holman et al. 1987, Myers and Fosbroke 1994, NIOSH 1997, Helmkamp and Derk 1999, Bentley et al. 2005), and this often occurs when a tree begins to displace during falling (Peters 1991). Thus, removing the faller from the base of the tree when it begins to displace can greatly improve safety. Previous research has shown that a new system consisting of two uncut strips, called tension strips (Fig. 1 ), can be used in conjunction with a remotely actuated hydraulic flange spreader to remove the faller from the base

of the tree when displacement is initiated (Noll and Lyons 2010). In previous research, it was found that the tension strips were more reliable if they were designed to fail in shear rather than axial tension. Horizontal cuts were bored into the tree below the tension strips in order to create a shear failure, and these cuts were termed the weakening cuts. It was also found in the previous research that the faller preferred to vary the vertical distance between the backcut and the weakening cuts to accommodate tree strength and imbalance. However, minor tree imbalance is a combination of lean, sweep, and crown asymmetry and this can be difficult to judge. It is not uncommon for a faller to call a minor imbalance in the direction of fall only to have the tree sit back and require wedging. The vertical distance between the backcut and the weakening cuts should be sufficient to ensure that trees with a modest imbalance in the direction of fall do not begin to move until the faller is in the clear; however, there still needs to be sufficient reserve strength in the spreader to initiate falling if the imbalance was actually opposite to the direction of fall.

The objectives of this paper are 1) to determine the optimum distance between the backcut and the weakening cut that maximizes the rate of success, and 2) to determine whether using one tension strip, as opposed to two, reduces the rate of success. Three datasets will be considered in the following analysis. The first dataset comes from a sample of 62 trees where the distance between the plane of the backcut and the weakening cut was selected randomly from $5 \mathrm{~cm}, 7.5$ $\mathrm{cm}$, and $10 \mathrm{~cm}$; this dataset will be called Dataset 1 . The second dataset comes from a sample of 67 trees where only one tension strip was used while the other dimensions were fixed

\footnotetext{
${ }^{1}$ Associate Professor, Dept. of Forest Resources Management, University of British Columbia, 2424 Main Mall, Vancouver, British Columbia V6T 1Z4, Corresponding author. E-mail: kevlyons@interchange.ubc.ca

${ }^{2}$ Assistant Engineer, INTERFOR, 1250 Ironwood Street, Campbell River, British Columbia V9W 6H5. E-mail: florian.noll@interfor.com
} 


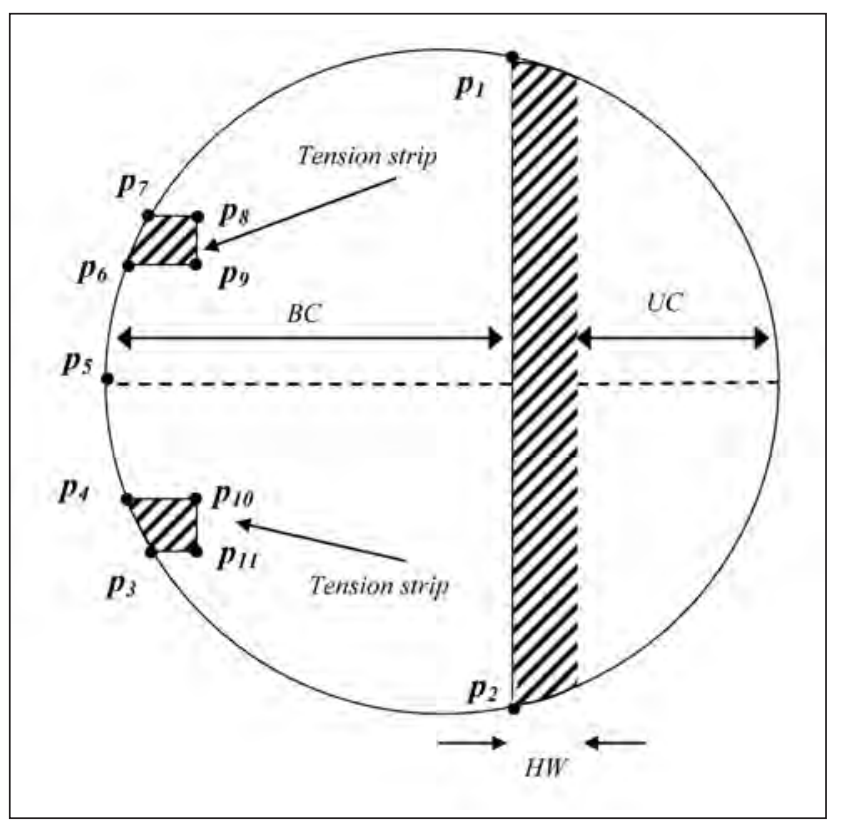

Fig. 1. Plan view holding wood design (for the one tension strip design remove $\mathrm{p6}$ to $\mathrm{p} 9$ )

at the optimum value found from previous research; this dataset will be called Dataset2. The third dataset is the intersection of Dataset 1 and Dataset 2 including all the trees that had a target distance between the backcut and the weakening cut of $7.5 \mathrm{~cm}$ (89 trees); this dataset permits comparison of trees with one tension strip to those with two and will be called Dataset 3 .

\section{Methods}

The field trials for all datasets were conducted at the Malcolm Knapp Research Forest (MKRF) during the summer of 2009 and the spring of 2010. All trees used in the field trial were 70to 75 -year-old second growth from natural regeneration after fire. Trees that were smaller than $30 \mathrm{~cm} \mathrm{DBH}$ were not used in this research, due to insufficient room behind the holding wood to bore the backcut and to form the tension strips. Trees were sampled in the order that the faller normally worked the stand. The research conducted for this paper used the same hydraulic flange spreader as used by Noll and Lyons (2010), which had a maximum separation force of $44.5 \mathrm{kN}$ (10 000 lb). The method used to design the cuts follows those developed by Noll and Lyons (2010). In the following, UC is the horizontal depth of the undercut, $B C$ is the depth of the backcut, and $H W$ is the width of the holding wood. Two different tension strip patterns were used in this study (Fig. 1). The external corners of all the features were marked in the field ( $p 1$ to $p 7$ for the two tension strip system and $p 1$ to $p 4$ for the one tension strip system). The depth of the line $p 8$ to $p 11$ (two tension strip system) and the line $p 10$ to $p 11$ (one tension strip system), were marked on the
Table 1. Target dimensions

\begin{tabular}{|c|c|c|c|c|}
\hline & Dimension & Distance $(\mathrm{cm})$ & Dimension & Distance $(\mathrm{cm})$ \\
\hline $\begin{array}{l}\text { Dataset1 } \\
\text { (Two } \\
\text { tension } \\
\text { strips) }\end{array}$ & $\begin{array}{c}U C \\
H W \\
B C \\
p 7 \text { to } p 8 \\
p 8 \text { to } p 9\end{array}$ & $\begin{array}{c}(1 / 3) \text { Diameterstump } \\
3 \\
(2 / 3) \text { Diameterstump } \\
4 \\
4\end{array}$ & $\begin{array}{c}p 4 \text { to } p 10 \\
p 10 \text { to } p 11 \\
p 4 \text { to } p 6 \\
d_{1}^{T}\end{array}$ & $\begin{array}{c}4 \\
4 \\
15 \\
5,7.5,10\end{array}$ \\
\hline $\begin{array}{l}\text { Dataset2 } \\
\text { (One } \\
\text { tension } \\
\text { strip) }\end{array}$ & $\begin{array}{c}U C \\
H W \\
B C \\
p 4 \text { to } p 10\end{array}$ & $\begin{array}{c}(1 / 3) \text { Diameterstump } \\
3 \\
(2 / 3) \text { Diameterstump } \\
6.5\end{array}$ & $\begin{array}{c}p 10 \text { to } p 11 \\
p 5 \text { to } p 4 \\
d_{1}^{T}\end{array}$ & $\begin{array}{l}6.5 \\
7.5 \\
7.5\end{array}$ \\
\hline
\end{tabular}

Spreader in extended position

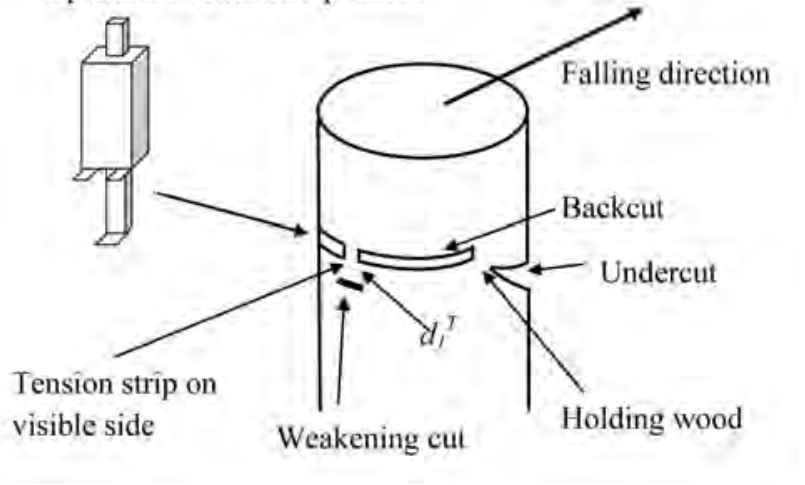

Fig. 2. Holding wood design side view

side of the tree to show the target dimensions for the faller to cut. The target distance between the weakening cuts and the plane of the backcut is called $d_{1}^{T}$ (Fig. 2), where $d_{1}^{T}$ is a class variable with three levels. Target dimensions for the falling cuts used in the field tests conducted for this paper can be found in Table 1.

The following process was used to makes the cuts for the two tension strip system identified in Fig. 1) The faller cut a Humboldt undercut with a horizontal depth approximately equal to one-third the diameter of the stump. 2) The faller inserted the saw between $p 1$ and $p 7$ and bored horizontally through the tree, he then brought the blade towards the undercut to form the holding wood. 3) With the saw still in the backcut the tip was pushed towards $p 5$, the objective of this cut was to mark the plane of the backcut at $p 5$. The saw was then removed from the backcut and inserted at $p 5$, keeping the saw perpendicular to the holdingwood the cut was brought towards $p 6$ and then back to $p 4$ completing the tension strips. If necessary the faller would trim the tension strips into $p 7$ and $p 3$ to form the correct dimensions. 4) Once the tension strips had been formed the faller bored into the tree directly below each tension strip (Fig. 2) to form the weakening cuts. Once all the cuts were completed the faller inserted the flange spreader and retreated to a safe position. A similar process was used to make the cuts for the one tension strip system, except the faller did not have to push the tip through to $p 5$ and only one tension strip was cut ( $p 6$ to $p 9$ eliminated in Fig. 1). 
Table 2. Data Summary for Dataset1

\begin{tabular}{|c|c|c|c|c|c|c|c|c|}
\hline$d_{1}^{T}$ & $n$ & $\begin{array}{c}\text { Mean } \\
\text { diameter } \\
(\mathrm{cm})\end{array}$ & $\begin{array}{l}\text { Western } \\
\text { hemlock }\end{array}$ & Douglas-fir & $\begin{array}{l}\text { Western } \\
\text { red } \\
\text { cedar }\end{array}$ & $S=1$ & $S=0^{\mathrm{a}}$ & $S=0^{b}$ \\
\hline 5 & 20 & 59.1 & 15 & 4 & 1 & 16 & 3 & 1 \\
\hline 7.5 & 22 & 59.6 & 19 & 3 & 0 & 20 & 2 & 0 \\
\hline 10 & 20 & 61.9 & 15 & 1 & 4 & 14 & 2 & 4 \\
\hline
\end{tabular}

${ }^{a}$ Tree fell before faller in the clear

bFlange spreader unable to initiate falling

Table 3. Data Summary for Dataset2

\begin{tabular}{lccccc}
\hline Species & $\boldsymbol{n}$ & $\begin{array}{c}\text { Mean } \\
\text { diameter } \\
(\mathbf{c m})\end{array}$ & $\mathbf{S = 1}$ & $\boldsymbol{S}=\mathbf{0}^{\mathbf{a}}$ & $\boldsymbol{S}^{\prime} \mathbf{0}^{\mathbf{b}}$ \\
\hline western red cedar & 34 & 82.8 & 26 & 2 & 6 \\
Douglas-fir & 3 & 69.0 & 1 & 0 & 2 \\
western hemlock & 30 & 53.4 & 25 & 2 & 3 \\
\hline
\end{tabular}

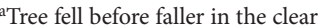

${ }^{b}$ Flange spreader unable to initiate falling

Table 4. Data Summary for Dataset3

\begin{tabular}{|c|c|c|c|c|c|c|}
\hline$T S(1)$ & Species & $n$ & $\begin{array}{c}\text { Mean } \\
\text { diameter } \\
(\mathrm{cm})\end{array}$ & $S=1$ & $S=0^{\mathrm{a}}$ & $S=0^{b}$ \\
\hline 34 & western red cedar & 34 & 82.8 & 26 & 2 & 6 \\
\hline 3 & Douglas-fir & 6 & 72.0 & 3 & 1 & 2 \\
\hline 30 & western hemlock & 49 & 54.9 & 43 & 3 & 3 \\
\hline
\end{tabular}

aTree fell before faller in the clear

bFlange spreader unable to initiate falling

Two explanatory variables were recorded before a tree was felled, tree imbalance and species. An imbalance of a tree is defined as the center of gravity of the tree not being directly over the center of the stump. It was assumed that imbalance would strongly affect the success of the novel manual tree falling system; however, imbalance is difficult to measure since it is the combined effect of lean, sweep, and an asymmetric crown. Fallers are experienced in estimating the direction of imbalance and so in this study the faller was asked to estimate the direction and magnitude of imbalance, where a major imbalance indicates the faller is confident in the direction of imbalance, while minor imbalance indicates the imbalance is small and could be in a direction other than that specified by the faller. Tree imbalance (Imbalance) is a class variable with three levels. Imbalance(1) is defined as a major imbalance in the direction of fall and Imbalance(2) is defined as a major imbalance opposite to the direction of fall. Imbalance( 0$)$ denotes a minor imbalance in any direction or a major imbalance sideways from the direction of fall. Tree species (Spcode) was recorded as a class variable with two levels, where Spcode(1) indicates western redcedar (Thuja plicata Donn ex D. Don) and Spcode(2) indicates either Douglas-fir (Pseudotsuga menziesii [Mirb.] Franco) or western hemlock
(Tsuga heterophylla [Raf.] Sarg.). Douglas-fir and western hemlock were combined into Spcode(2) because of the low numbers of Douglas-fir sampled, and their similar mechanical properties (Green et al. 1999).

The faller was given the target dimensions described above; however, the researcher did not interfere during the cutting process after marking the dimensions. The actual dimensions of the cuts were a function of the faller's ability to accurately cut to the prescribed points. Thus, the total tree height in meters (Height), the average diameter measured outside bark at stump height (Diameterstump), the total cross section area of the tension strips as a product of depth and width (TCA), and the actual distance between the plane formed by the backcut and the weakening cuts $\left(d_{1}^{P F}\right)$ were measured after the tree was on the ground as post-falling measurements. Note in Dataset 1 for the postfalling measurements that $d_{1}^{P F}$ is the minimum of the two distances actually cut for the two tension strips, and that $d_{1}^{P F}$ is a continuous variable for all the datasets considered in this paper. The falling method can have two possible outcomes failure $(S=0)$ and success $(S=1)$, where $S=1$ indicates the tree did not move until the faller was in the clear and the hydraulic flange spreader was able to initiate falling. A summary of the post-falling data for each dataset is given in Tables 2,3 and 4 . Note, since $S$ is a binary variable logistic regression will be employed when $S$ is used as the response variable.

\section{Results}

\section{Results for Dataset1}

Recall that Dataset 1 uses two tension strips and that the dimensions for $d_{1}^{T}$ were randomly selected from $5 \mathrm{~cm}, 7.5 \mathrm{~cm}$, and $10 \mathrm{~cm}$. The success rate for the $d_{1}^{T}$ target values of $5 \mathrm{~cm}$, $7.5 \mathrm{~cm}$, and $10 \mathrm{~cm}$ are respectively $0.8,0.91$, and 0.7 , where success rate is defined as the number of successes dived by the number of observations for the target value. When using the target dimensions the success rate is highest when $d_{1}^{T}$ is $7.5 \mathrm{~cm}$.

In the following logistic regression analysis the actual postfalling dimensions of $d_{1}^{P F}$ will be considered a continuous variable, and as can be seen from the $d_{1}^{T}$ success rates, $d_{1}^{P F}$ will likely have a non-linear relationship with success and so a second order relationship will be assumed. In order to determine if $d_{1}^{P F}$ and $\left(d_{1}^{P F}\right)^{2}$ are significant in explaining the variation in $S$ consider the following two models.

$$
\begin{aligned}
& \text { [1] } S_{i}=\beta_{0}+\epsilon_{i} \\
& \text { [2] } S_{i}=\beta_{0}+\beta_{1} d_{1}^{P F}+\beta_{2}\left(d_{1}^{P F}\right)^{2}+\epsilon_{i}
\end{aligned}
$$

Here $\beta_{0}$ is the intercept, $\epsilon_{i}$ is the error term, $i=1, \ldots, n$ observations, $\beta_{1}$ to $\beta_{2}$ are the coefficients for $d_{1}^{P F}$ and $\left(d_{1}^{P F}\right)^{2}$.

Eq. 1 is nested within eq. 2 ; therefore, they can be tested using the Likelihood Ratio Test (LRT). Setting eq. 2 as the full model and eq. 1 as the reduced model the test statistic is $-2 \lambda=60.925-55.115=5.81$ using maximum likelihood (ML), thus, $d_{1}^{P F}$ and $\left(d_{1}^{P F}\right)^{2}$ are significant in explaining the variation in $S\left(\chi^{2}, d f=2, p=0.0547\right)$. Including the coefficients 
found when fitting eq. 2 to Dataset 1 results in

$$
\text { [3] } S=4.6328+1.7160 d_{1}^{P F}-0.1102\left(d_{1}^{P F}\right)^{2}
$$

Take the first derivative of eq. 3 with respect to $d_{1}^{P F}$, set the result to zero, and solve for $d_{1}^{P F}$. The value for $d_{1}^{P F}$ that maximizes success is $7.8 \mathrm{~cm}$, which is similar to the target dimension result of $7.5 \mathrm{~cm}$. Thus, this paper will use $7.5 \mathrm{~cm}$ as the preferred target dimension for $d_{1}^{T}$.

\section{Results for Dataset2}

Recall that Dataset 2 uses only one tension strip with the target value for $d_{1}^{T}$ fixed at $7.5 \mathrm{~cm}$. To examine whether Spcode, Diameterstump, Height and Imbalance are significantly correlated with success, consider the following three models.

$$
\begin{aligned}
\text { [4] } S_{i}= & \beta_{0}+\epsilon_{i} \\
{[5] \quad S_{i}=} & \beta_{0}+\beta_{1} \text { Imbalance }(1)+\beta_{2} \text { Imbalance }(2)+\epsilon_{i} \\
\text { [6] } S_{i}= & \beta_{0}+\beta_{1} \text { Imbalance }(1)+\beta_{2} \text { Imbalance }(2)+\beta_{3} \text { Spcode (2) } \\
& +\beta_{4} \text { Diameterstump }(2)+\beta_{5} \text { Height }(2)+\epsilon_{i}
\end{aligned}
$$

Here $\beta_{0}$ is the intercept, $\epsilon_{i}$ is the error term, $i=1, \ldots, n$ observations, $\beta_{1}$ to $\beta_{5}$ are the coefficients for Imbalance, Spcode, Diameterstump, and Height, where Spcode(2) and Imbalance $(0)$ have been assigned to the reference level.

Setting eq. 6 as the full model and eq. 5 as the reduced model the LRT test statistic is $-2 \lambda=50.452-51.257=0.805$ using ML; therefore, the variables Diameterstump, Height, and Spcode in eq. 6 are not significant $\left(\chi^{2}, d f=3, p=0.8482\right)$. This result indicates success is insensitive to these variables over the range considered in this dataset. Using LRT and setting eq. 5 as the full model and eq. 4 as the reduced model the test statistic is $-2 \lambda=71.258-51.257=19.001$ using ML; therefore, the variable Imbalance is significant for this data set $\left(\chi^{2}, d f=2, p=0.00007\right)$. The results for Dataset 2 are similar to what Noll and Lyons (2010) concluded for a two-strip design, which also showed that diameter, height and species were not significantly correlated with success.

Recall that Imbalance(1) is a major imbalance in the direction of fall, Imbalance (2) is a major imbalance opposite to the intended direction of fall, and Imbalance( $(0)$ is a minor imbalance in any direction or a major imbalance sideways. Considering the parsimonious model eq. 5 the odds ratio estimate for Imbalance(1) compared to Imbalance(0)was 0.192; $95 \%$ Confidence Interval, 0.037-1.002, indicating the chance of successfully falling a tree is $81 \%$ lower when it is associated with Imbalance (1). When comparing Imbalance (2) to Imbalance $(0)$ the odds ratio was $0.029 ; 95 \%$ Confidence Interval, $0.005-0.170$, indicating the chance of successfully falling a tree is $97 \%$ lower when it is associated with Imbalance(2). These results highlight the optimization problem that results from using a relatively small hydraulic flange spreader. If the tension strips are too small they are not strong enough to support a tree with a major imbalance in the direction of fall; however, if the tensions strips are too large then the hydraulic flange spreader is not strong enough to break the tension strips if there is a major imbalance opposite to the direction of fall. In order to increase the success rate for trees with major imbalance it will be necessary to increase the separation force supplied by the falling tool; however, this must be done without greatly increasing the weight of the tool.

\section{Results for Dataset3}

Note that Dataset 3 combines the observations from Dataset 1 with $d_{1}^{T}$ equal to $7.5 \mathrm{~cm}$ and all observations from Dataset2, and that Dataset 1 used two tension strips and that Dataset 2 used one tension strip. This permits a comparison between the two and one tension strip designs. The variable TS will be included as a class variable with two levels, where TS(2) represents observations with two tension strips and TS(1) represents observations with one tension strip. In order to determine if TS is significant in explaining the variation in $S$, consider the following four models.

[7] $S_{i}=\beta_{0}+\epsilon_{i}$

[8] $S_{i}=\beta_{0}+\beta_{1} \operatorname{Imbalance}(1)+\beta_{2} \operatorname{Imbalance}(2)+\epsilon_{i}$

[9] $S_{i}=\beta_{0}+\beta_{1}$ Imbalance (1) $+\beta_{2} \operatorname{Imbalance}(2)+\beta_{3} T S(1)+\epsilon_{i}$

[10] $S_{i}=\beta_{0}+\beta_{1} \operatorname{Imbalance}(1)+\beta_{2} \operatorname{Imbalance}(2)+\beta_{3} \operatorname{Spcode}(2)$ $+\beta_{4}$ Diameterstump $(2)+\beta_{5}$ Height $+\beta_{6}$ TS $(1)+\epsilon_{i}$

Here $\beta_{0}$ is the intercept, $\boldsymbol{\epsilon}_{i}$ is the error term, $i=1, \ldots, n$ observations, $\beta_{1}$ to $\beta_{6}$ are the coefficients for Imbalance, Spcode, Diameterstump, Height and TS. Recall Spcode is a class variable with two levels, Imbalance is a class variable with three levels and TS is a class variable with two levels; Spcode(2), Imbalance (0) and TS (2) have been assigned to the reference level.

Setting eq. 10 as the full model and eq. 9 as the reduced model the LRT test statistic is $-2 \lambda=68.248-65.397=2.851$ using ML; therefore, the variables Diameterstump, Height and Spcode in (10) are not significant $\left(\chi^{2}, d f=3, p=0.4151\right)$. Setting eq. 9 as the full model and eq. 8 as the reduced model the LRT test statistic is $-2 \lambda=71.294-68.248=3.046$ using ML; therefore, the variable TS in eq. 9 is not significant $\left(\chi^{2}, d f=\right.$ $1, p$-value $=0.081)$ in explaining the variation in $S$. Unfortunately, the effect of the number of tension strips is confounded with location since Dataset1 and Dataset2 were taken from two different locations. Changing location could result in changes in tree form (that are not captured by height and diameter), wood strength, and weather. Thus, since TS is not significant in explaining the variation in $S$ this could mean either 1) neither the number of tension strips nor the location had a significant effect on $S$, or 2) the effect of the number of tension strips cancelled out the effect of location. Note when considering eq. 8 as the full model and eq. 7 as the reduced model that Imbalance is again significant $\left(\chi^{2}, d f=2, p\right.$ $=0.00004)$ over the range considered in this dataset.

\section{Conclusions}

This paper reports the results from two different field trials using manual tree falling techniques that were similar to those reported by Noll and Lyons (2010). In the first field trial 62 trees were tested using two tension strips, while varying $d_{1}^{T}$, and the results of this paper indicate that the optimum target value for $d_{1}^{T}$ is $7.5 \mathrm{~cm}$. In the second field trial 67 trees were 
tested using a single tension strip when holding the target value for $d_{1}^{T}$ fixed at $7.5 \mathrm{~cm}$. When considering the results from the second field trial they appear to be very similar to those found by Noll and Lyons (2010). Specifically, the one tension strip system was insensitive to factors such as tree species and size within the range consider in the tests, and had a success rate of $78 \%$. The observations from the first field trial that used a $7.5 \mathrm{~cm}$ value for $d_{1}^{T}$ were combined with the observations from the second field trial, in order to obtain a comparison between the two tension strip system and the one tension strip system. When considering this combined dataset, and including the class variable TS to indicate whether one or two tension strips were used, it was found that $T S$ was not significant in explaining the variation in $S$. Since $T S$ was not significant it may be possible to infer that using two tension strips does not significantly increase the rate of success, and since the faller found cutting one tension strip was much simpler than two, one tension strip should be the preferred design. The caveat with this observation is that TS is confounded with location since the two trials were conducted in different locations and only one level of TS was used at each location; thus, the effect of location could be cancelling the effect of the number of tension strips.

This research has been constrained by the desire to minimize the weight of the separation tool; therefore, the separation force has been limited to $44.5 \mathrm{kN}$. The relatively small separation force limits the maximum size of the tension strips and for trees that are imbalanced in the direction of fall this can result in failure where the tree displaces before the flange spreader is inserted. Additionally the relatively small separation force limits the ability of the flange spreader to overcome an imbalance opposite to the direction of fall. Thus, a tool with a larger separation force would permit the use of larger tension strips while still having a sufficient reserve to initiate falling of trees with significant imbalance opposite to the direction of fall. Future research will concentrate on developing such a tool.

\section{Acknowledgements}

This research is supported with funds from WorkSafe BC (grant RS2008-OG03)

\section{References}

Bentley T.A., R.J. Parker and L. Ashby. 2005. Understanding felling safety in the New Zealand forest industry. Applied Ergonomics. 36(2): 165-175.

Green, D. W., J.E. Winandy and D.E. Kretschmann. 1999. Wood handbook : wood as an engineering material. USDA Forest Service. Forest Products Laboratory. Madison, WI. GTR-113.

Helmkamp, J.C. and S.J. Derk. 1999. Nonfatal Logging-Related Injuries in West Virginia. Journal of Occupational and Environmental Medicine. 41: 967-972.

Holman G.R., A. Olszewski and R.V. Maier.1987. The Epidemiology of Logging Injuries in the Northwest. The Journal of Trauma 27(9): 1044-1050.

Myers J.R. and D.E. Fosbroke. 1994. Logging Fatalities in the United States by Region,

Cause of Death, and Other Factors -1980 through 1988. Journal of Safety Research 25(2): 97-105.

[NIOSH] National Institute for Occupational Safety and Health. 1997. Occupational Mortality in Washington State 1950-1989. DHHS (NIOSH) Publication No. 96-13 [online]. Available at http://www.cdc.gov/niosh/pdfs/96-133.pdf [Accessed 05/11/2010].

Noll, F.M. and C.K. Lyons. 2010. A novel method for manually falling trees. The Forestry Chronicle. 86(5): 608-613.

Peters, P.A. 1991. Chainsaw Felling Fatal Accidents. Transactions of the ASAE 34(6): 2600-2608.

Paulozzi, L.J. 1987. Fatal logging injuries in Washington state. Journal of Occupational

Medicine 29(2): 103-108.

WorkSafeBC. 2004. Faller Certification Backgrounder [online]. Available at http://www.worksafebc.com/news_room/Assets/PDF/04_ 11_04/BackgrounderFallerCertification.pdf [Accessed 05/11/2010]. WorkSafeBC. 2009. Occupational Health and Safety Faller Serious Injury and Fatal Review 2009 [online]. Available at http://www2. worksafebc.com/pdfs/forestry/Faller_Review_2009.pdf [accessed 03/04/2010]. 